\title{
Las ciudades de Rosângela Doin
}

\author{
Rosângela Doin \\ Artista y Doctora en Educación. Universidad de San Pablo.
}

\author{
Verónica Hollman \\ CONICET - Universidad de Buenos Aires. Facultad de Filosofía y Letras. Instituto de Geografía "Romualdo Ardissone". \\ Buenos Aires, Argentina.
}

Las ciudades de Rosângela Doin nos emocionan: cada una de ellas nos abre, como diría Maurice Merleau Ponty, a un conocimiento sensible y de transformación activa de nuestro mundo. Tal vez, mirar las obras de las series Polis y Skyline remita a trazos de una búsqueda en torno a los modos posibles de grafiar la experiencia de (co)habitar una ciudad. Rosângela Doin imagina, dibuja, pinta otras ciudades posibles y con ellas, otros modos de vivirlas.

Como si se tratara de un interminable cuaderno de notas, ocurrencias, conexiones, ideas, tachaduras, su trabajo como geógrafa en los campos de la educación, la investigación y la producción de atlas escolares constituye el anclaje de su producción artística. ${ }^{1}$ Rosângela Doin explora y combina diversas técnicas en sus obras -acuarela, lápiz, grabado, collage, ecoline-. Ese despliegue de técnicas pareciera inscribir en sus obras una de las preocupaciones que atraviesa su trayectoria como geógrafa: los lenguajes, particularmente el lenguaje cartográfico, como entramados de posibilidades abiertas a partir de las cuales se "crea un campo temporal que resulta tan real y perceptivo como visual” (Doin, 1994:9). Con cada técnica que elige utilizar y ensamblar, Rosângela inscribe el propio acto de grafiar el espacio como potencia creativa (Oliveira, 2009). Quien mira elegirá atravesar o no esos umbrales, desplazarse en las discontinuidades que presenta cada una de sus obras o detener la mirada en esos reversos que los diseñadores urbanos infructuosamente intentan esconder a los ojos de los urbanitas, ya se trate de habitantes o turistas.

Las ciudades de Rosângela se presentan desde el punto de vista vertical, a vuelo de pájaro, de frente; también

1 Una exhaustiva revisión de la trayectoria de Rosângela Doin puede encontrarse en Gonçalves y Seneme do Canto (2019). con distintos niveles de proximidad -desde la intimidad de una vivienda que se despliega como las partes de una maqueta lista para ser armada, la cercanía de un árbol que toma el protagonismo del espacio y tiempo de un sujeto, hasta el anonimato que delinea una silueta urbana-. En algunas de sus obras inclusive hay combinaciones de puntos de vista y niveles de proximidad que inquietan nuestra experiencia visual de representación de la ciudad. Si se tratase de dibujos realizados por personas en situación de aprendizaje, la ausencia de un sistema de coordinación de puntos de vista podría interpretarse como una dificultad para representar un espacio proyectivo. Sin embargo, quien ensambla esos de puntos de vista conoce en profundidad las reglas de representación del espacio proyectivo y euclidiano. Rosângela ha imaginado, propuesto y analizado metodologías para la transmisión del lenguaje cartográfico a las nuevas generaciones. Entiende que "en el orden del lenguaje se juega cómo nombramos lo que vemos y cómo vemos los que nombramos, cómo ponemos juntas las palabras y las cosas, cómo normatizamos o desnormatizamos nuestro modo de dar sentido al mundo y a nosotros mismos, en suma, cómo pensamos, cómo actuamos y cómo vivimos" (Larrosa, 2011 [1996]:64). Sus imágenes sugieren la experiencia de la precariedad, inestabilidad, arbitrariedad, limitaciones que entraña el lenguaje cartográfico; también de las potencias que se pueden abrir desde ese orden normativo.

Más allá del placer visual que estas obras nos provocan, ellas movilizan nuestro pensamiento. Si el conocimiento geográfico se organiza visualmente, podríamos preguntarnos si seremos capaces de des-normatizar los modos de grafiar el espacio que, como advierte Doreen Massey (2007 [2005]), siguen presentándolo como una superficie lisa y continua. Tal vez en la aproximación a otros lenguajes, no solo visuales, encontremos modos para hacerlo. 
A transformação das cidades é algo intrigante para mim. Todos os dias aparecem coisas novas: casas são demolidas, outras começam a ser construídas, surge um novo loteamento, derrubam uma árvore... No entanto, as cidades aparecem nas telas com formas inertes, duras, imutáveis. Mas como a constante modificação urbana pode aparecer em uma tela (não estou falando de vídeo ou cinema)?

Em uma única imagem eu queria que a transformação da cidade ficasse visível, mas não queria usar recursos gráficos típicos dos mapas. O tempo precisava aparecer no espaço da cidade. "É pelo espaço, é no espaço que encontramos os belos fósseis de uma duração concretizados em longos estágios" (Bachelard, 1988:115). Sim, mas como apresentar o tempo no espaço do papel? Não se trata apenas de técnicas, perspectivas ou materiais. Trata-se de criar algo que remeta o observador para além da imagem.

$\mathrm{O}$ artista busca uma imagem perfeita para se expressar, na qual cada elemento tem um lugar apropriado. “(...) uma obra de arte, forma acabada e fechada em sua perfeição de organismo perfeitamente calibrado, é também aberta, isto é, passível de mil interpretações diferentes, sem que isso redunde em alteração de sua irreproduzível singularidade" (Eco, 2003:40, grifo do autor). A composição dos elementos e a escolha das formas, texturas e cores são fundamentais em uma obra, embora para quem a observa seja difícil imaginar como esse intrincado processo ocorreu. Para o próprio artista, muitas vezes, a imagem surge dentro dele, antes de ir para o papel, revelando aquilo de si próprio que antes lhe era desconhecido.

Em Tempos permeáveis aparecem tempos que se sobrepõem na paisagem de uma cidade (não importa qual). Primeiro, desenhei um Skyline que, para indicar que é a forma daquilo que surgiu mais recentemente, achei que deveria ficar na parte superior da folha. Depois, desenhei, na parte inferior da folha, o casario pré-existente e que foi desaparecendo para dar lugar para os edifícios. Como eu poderia indicar a passagem constante de um tempo sobre outro? É aí que a imagem surge por si só, praticamente sem depender de minha criação. $\mathrm{Na}$ aquarela existe o recurso de soprar a tinta com um canudinho e criar escorridos ou linhas conforme a força do sopro. O movimento desses traços remete para algo que acontece entre os dois planos da imagem, e sugere a existência de algo entre eles que os liga e ao mesmo tempo os separa. Sugere a ideia de movimento e também de "passagem".
Na imagem Tempo e espaço de Thomáz Perina colei mapas em uma réplica que fiz de uma das principais obras desse importante artista do interior paulista. ${ }^{2}$ Escolhi dois mapas da cidade de Campinas (de 1878), um com a malha urbana e outro com pintura e identificação das principais edificações. A presença de fragmentos desses mapas colados sobre a obra de Perina pretende denotar que ela tomou existência em um lugar e em uma época, dando ao original uma nova dimensão.

O trabalho com a técnica de linóleo gravura me possibilitou diferentes imagens do traçado de um Skyline com a mesma matriz. Surge a série Skyline onde consegui justapor elementos urbanos com a associação de outras técnicas.

Ao trabalhar com a imagem da cidade, que trazia um traçado estático, apesar dos elementos justapostos como imagem de uma multidão, o desenho de uma planta urbana e até de pequenas casas, estava ausente o principal conflito social vivido nas grandes cidades: as favelas. A partir da observação de imagens de satélite de favelas do Rio de Janeiro, criei imagens com tinta ecoline porque permite fazer um efeito borrado e impreciso. Surgem as imagens da série Pólis.

Para brincar um pouco, fiz a obra Over View. Com um traçado imaginário e usando aquarela e muitas cores, essa imagem de vila significa, para mim, que a cidade também é divertida.

Rosângela Doin

\section{Bibliografía}

» Bachelard, G. (1988). A poética do espaço (R.F. Kuhnen, A.C. Leal y L.V.S. Leal, Trad.). San Pablo: Nova Cultural.

»Doin, R. (1994). Uma proposta metodológica para a compreensão de mapas geograficos. Tesis de Doctorado, Facultad de Educaión, Universidade de San Pablo.

2 Thomaz Perina (Campinas, São Paulo 1920 - 2009). Pintor, decorador, publicitário, professor, cenógrafo e figurinista. Inicia seus trabalhos em sua cidade natal, executando decorações para o Teatro Municipal Castro Mendes. Leciona pintura em seu ateliê -tendo como alunos Geraldo de Souza, Raul Porto, Maria Helena Motta Paes e Francisco Biojone- e desenho na Escola de Desenho e Tecnologia de Campinas (1940 a 1970). De 1957 a 1966, integra o Grupo Vanguarda e, de 1961 a 1975, o Grupo Hoje. Nesse último ano, faz a ornamentação arquitetônica para o Centro de Convivência Cultural de Campinas. Recuperado de: https://enciclopedia.itaucultural.org.br/pessoa9343/thomaz-perina 
» Eco, U. (2009). Obra aberta. Forma e indeterminação nas poéticas contemporâneas (G. Cutolo, Trad.). San Pablo: Perspectiva.

" Gonçalves, A. y Seneme do Canto, T. (2019, julio). Rosângela Doin de Almeida. Rotas pela Educação, Geografia e Cartografia Escolar. Anais do 14 ENPEG, Encontro Nacional de Prática de Ensino em Geografia. Políticas, linguagens e trajetórias, Unicamp. Recuperado de: https://ocs.ige.unicamp. br/ojs/anais14enpeg/index

»Larrosa, J. 2011. La experiencia de la lectura. Estudios sobre literatura y formación. México: Fondo de Cultura Económica. (Publicación original, 1996).

》 Massey, D. (2007). For space. Londres: Sage Editores. (Publicación original: 2005).

" Oliveira Jr., W. (2009). Grafar o espaço, educar os olhos. Rumo à geografias menores. Proposições, $20(3), 17-28$. 
ROSÂNGELA DOIN, VERÓNICA HOLLMAN

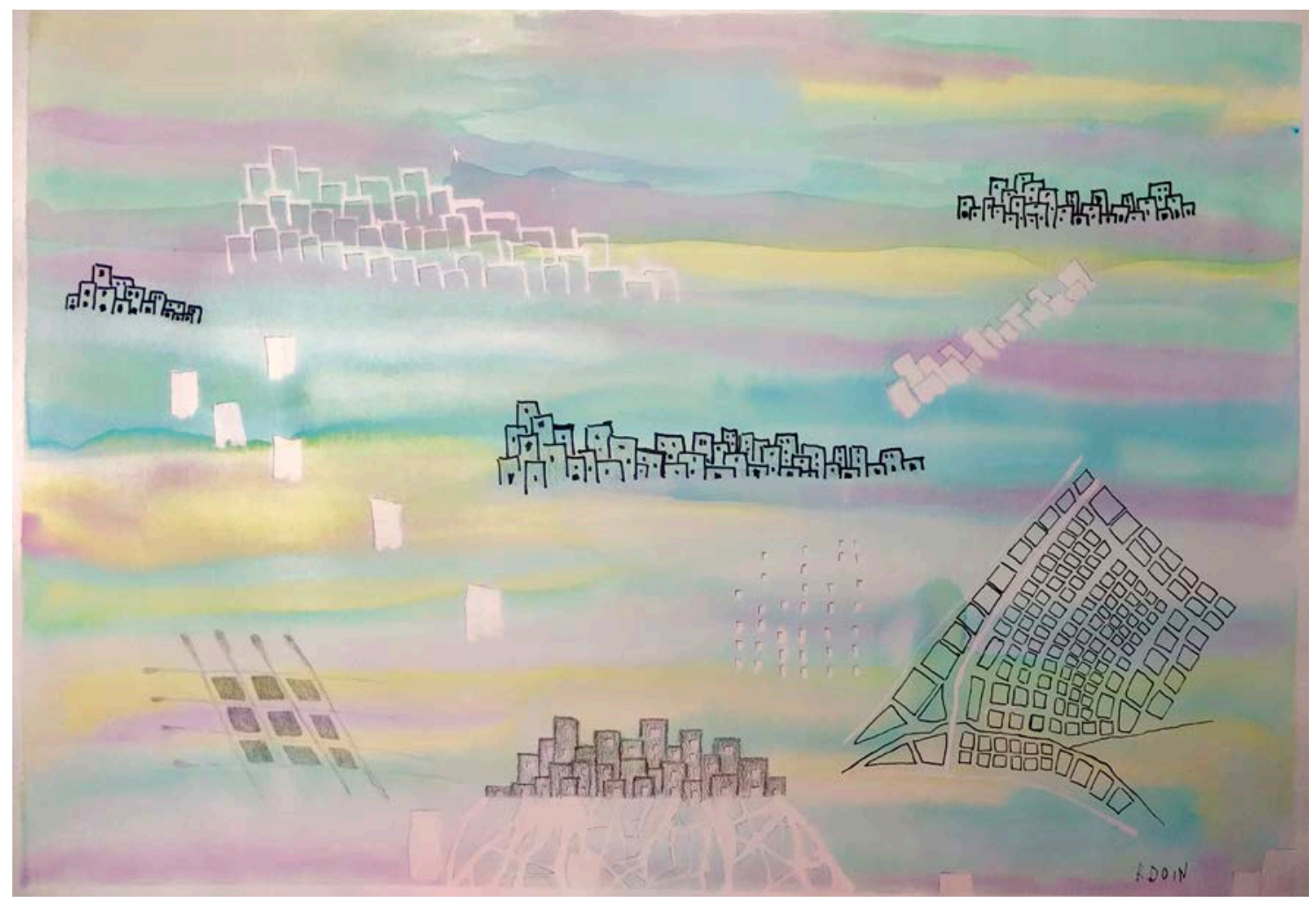

Cidade etérea. Serie "Polis". Ecoline sobre papel. 62 cm x 80 cm, 2018. 


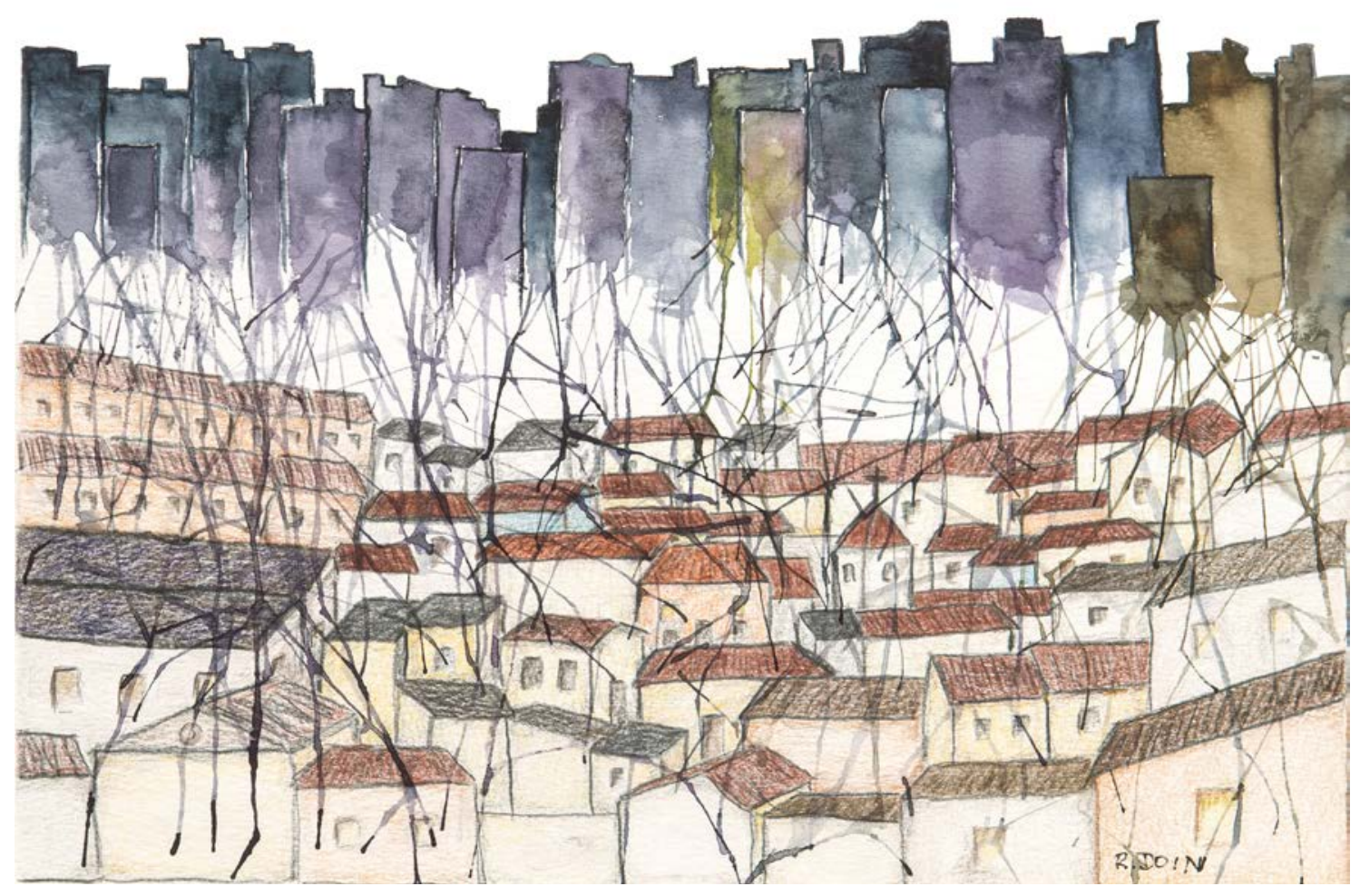

Tempos permeáveis. Série Polis. Acuarela y lápiz sobre papel. 60 x 48 cm, 2017 . 
RosÂngela DoIN, VERóNICA HOLLMAN

\section{Cidade Invisível}

Há cidades invisíveis, disse Calvino.

Não é possível ver a cidade?

Talvez só uma parte...

Se olhar do meio da rua

Dá para ver um pedaço

Dá para ver, se olhar de cima.

Se for de bem longe, vai parecer uma mancha...

No mapa: Formas visíveis.

Linhas retas, pequenos quadrados.

Tem gente aí?

Não consigo ver...

Rosângela Doin (Enero, 2019) 
RosÂngela DoIn, Verónica HolLMAN

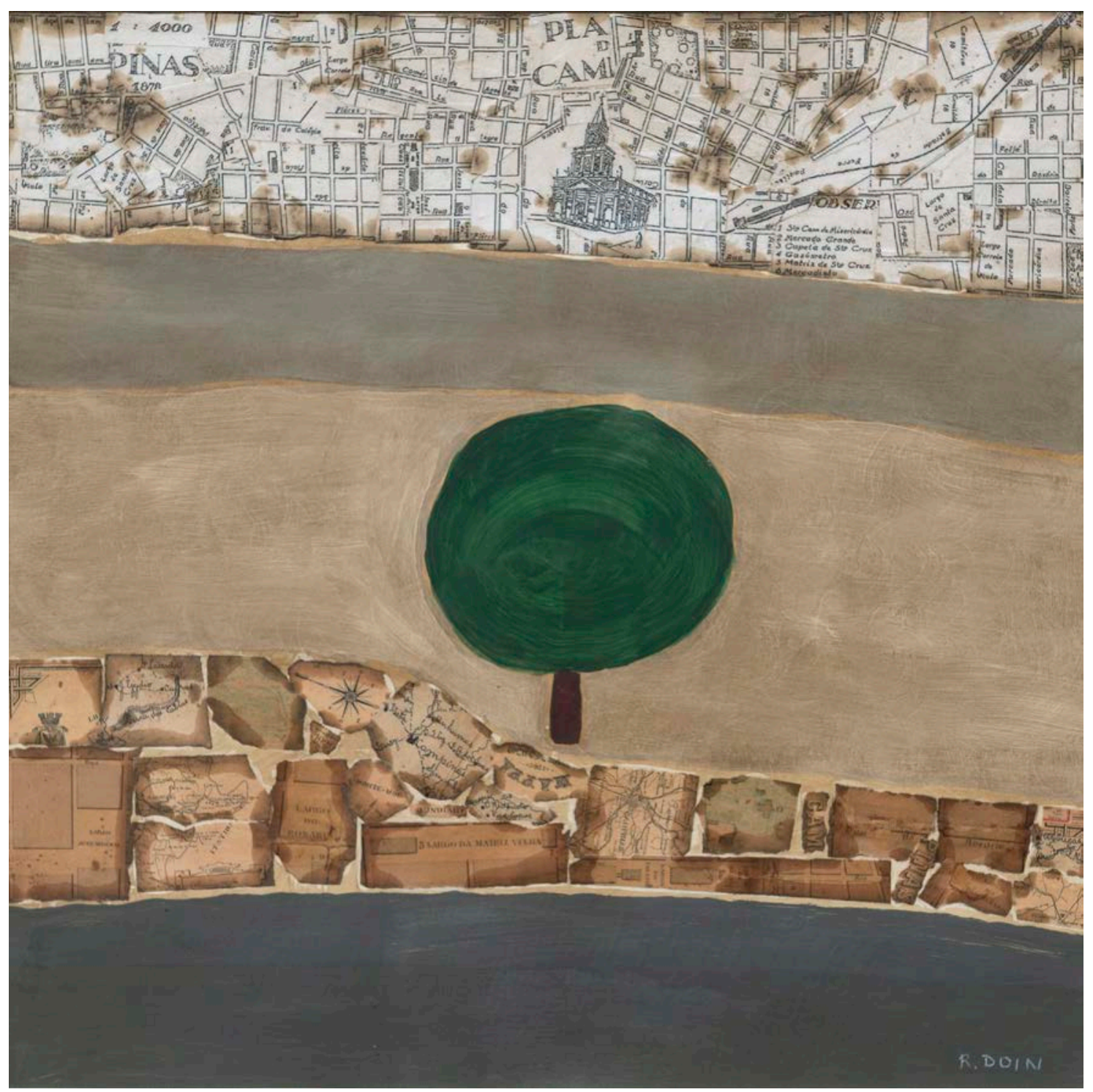

Espaço e tempo de Thomaz Perina. Serie "Polis". Pintura y collage sobre papel. 75 cm x 75 cm, 2016. 

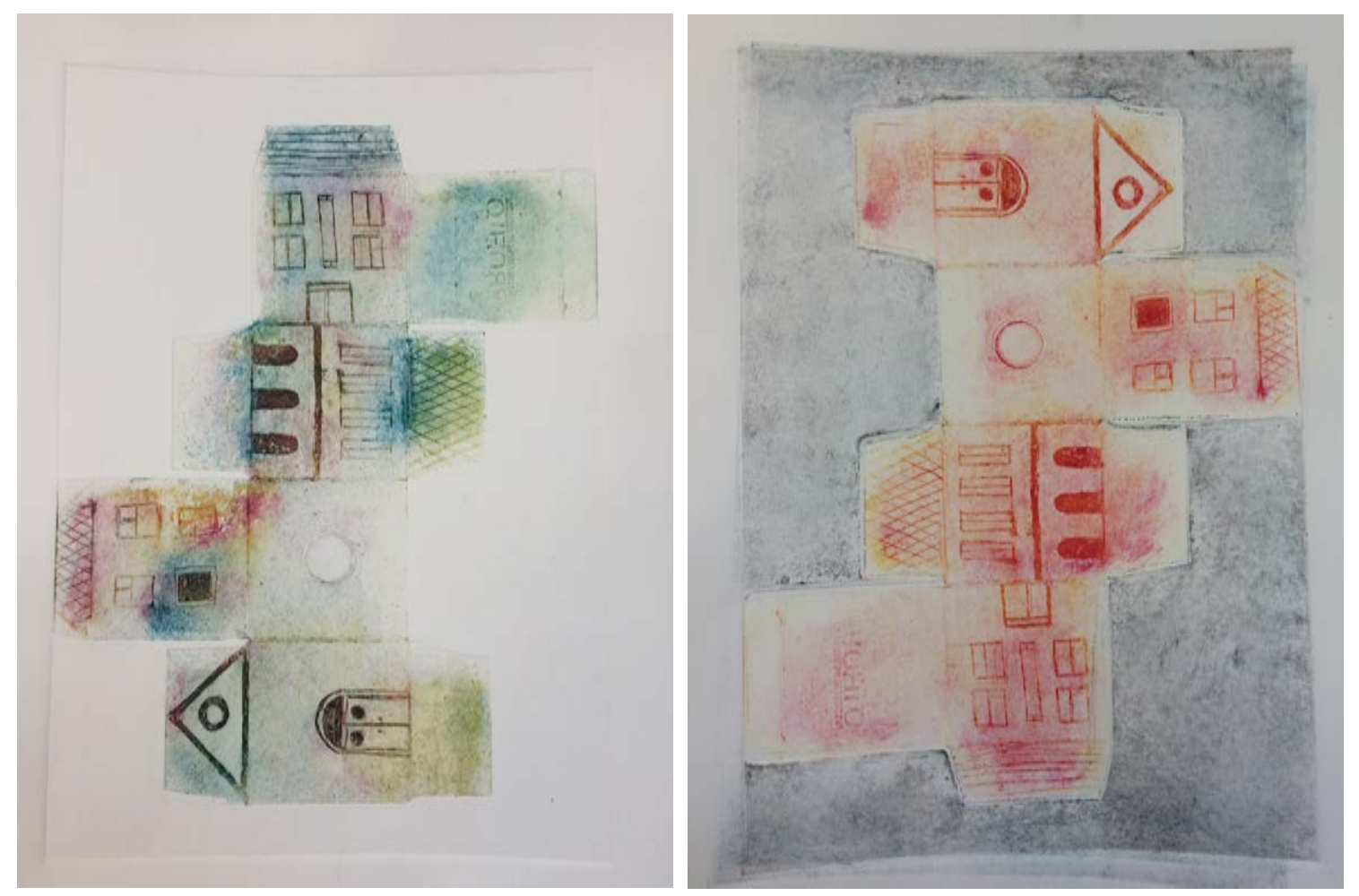

Casa de dois andares 1/2. Serie "Skyline". Acuarela y grabado sobre papel. $32 \mathrm{~cm}$ x $18 \mathrm{~cm}, 2017$.

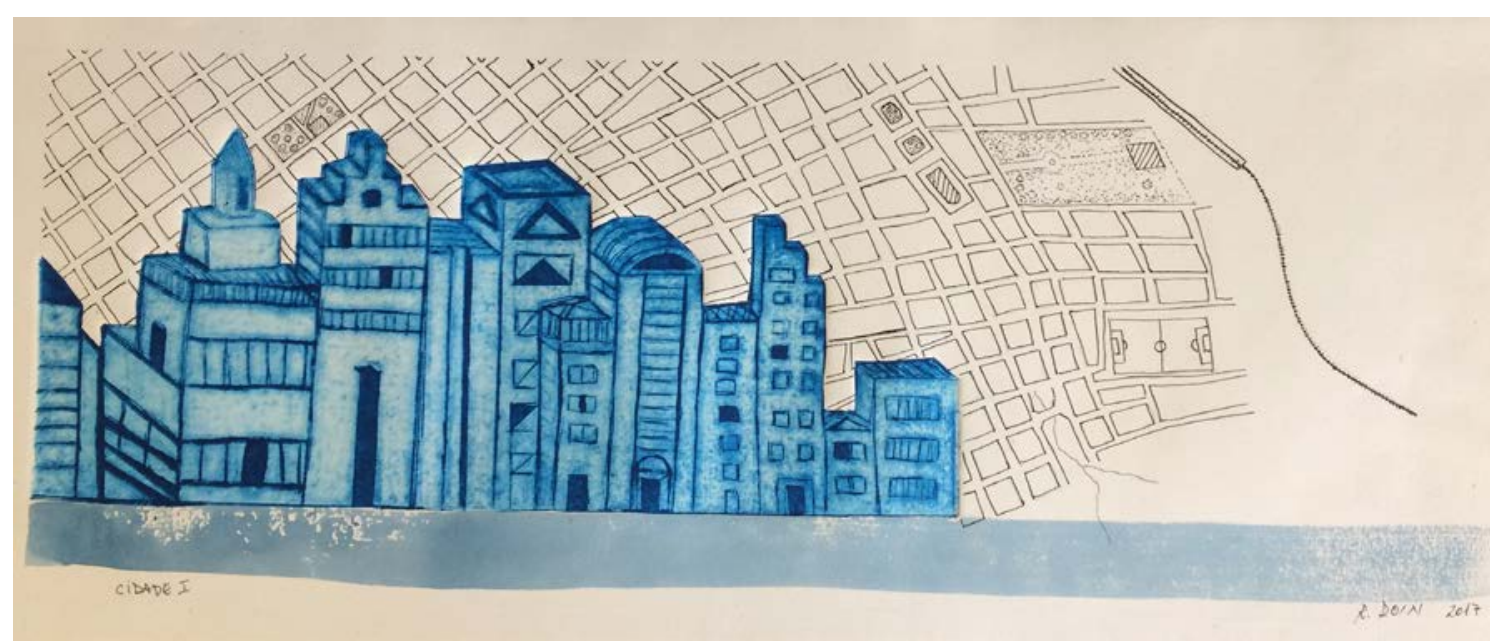

Fora do mapa. Serie "Skyline”. Acuarela, grabado y tinta sobre papel. 49 cm x 18 cm, 2017. 


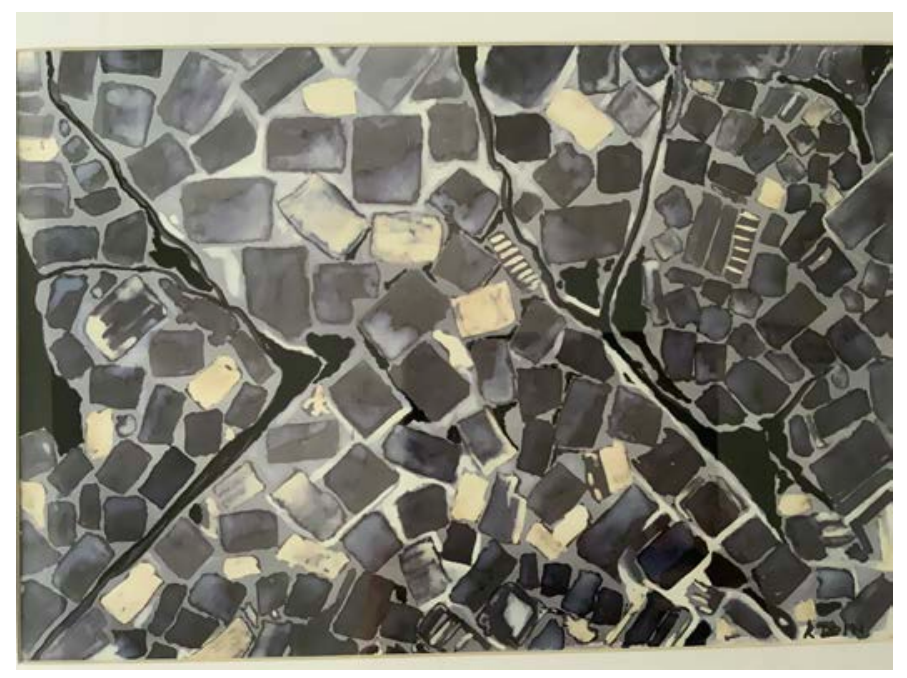

Shantytown 1. Serie "Polis". Ecoline sobre papel. 50cm x 62 cm., 2018.

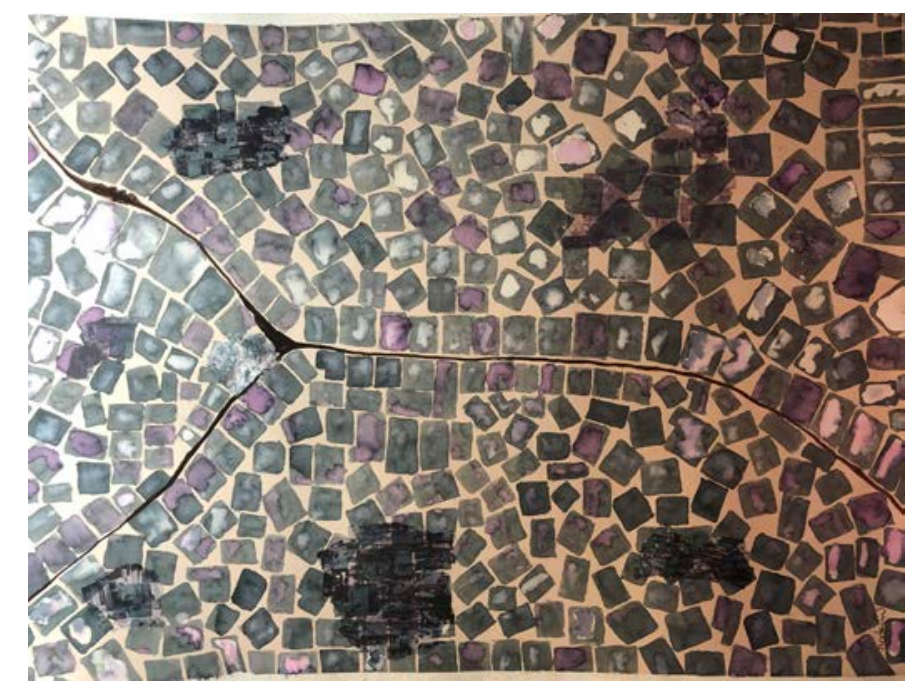

Big Shantytown 2. Serie "Polis". Ecoline sobre papel. 42 cm x 60 cm., 2018.

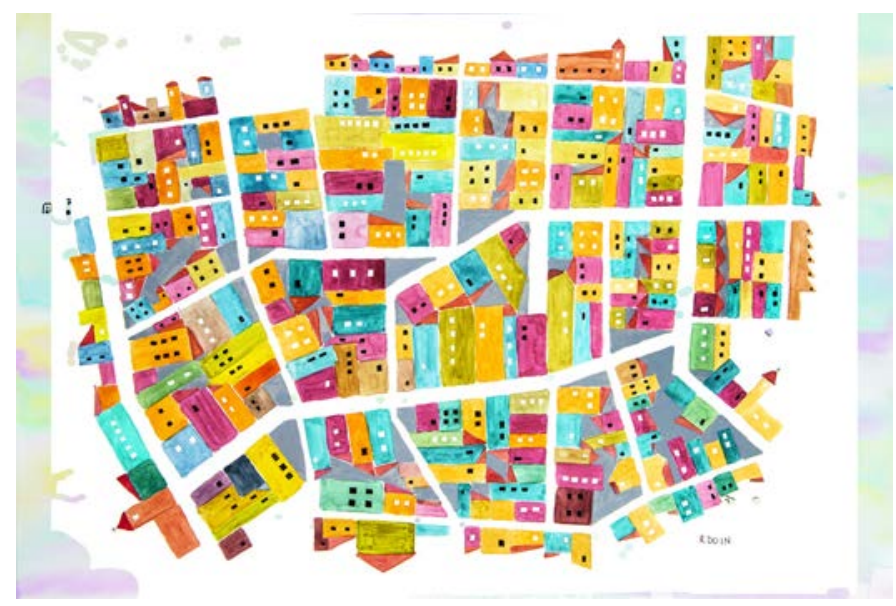

Over view. Serie "Polis". Acuarela sobre papel. 62 cm x 80 cm., 2019. 
Rosângela Doin / rda.doin@gmail.com / Instagram: @rodoinarte

Artista visual, geógrafa y diseñadora de interiores. Trabajó como profesora e investigadora en la Universidad Estatal Paulista-Campus Río Claro, hasta el año 2004. Estudió Diseño de Interiores en la Escuela de Arte y Diseño de Campiñas (2013-2015), restauración en madera con técnicas con Piero Caló (San Pablo, 2002), técnicas de arte contemporáneo en el Ateliê Tote con la artista Norma Vieira (Sousas, Campiñas, 2011). Desde 2016estudia y trabaja con técnicas de grabado, arte contemporáneo y acuarela en el Ateliê Vera Ferro (Campiñas). Recibió la medalla de oro con la fotografía "Pau ferro abatido na Rua Samambaia" en el Salão de Artes de Serra Negra 2002. Fue miembro del grupo N'Arte (Río Claro, 2000 a 2004). Expuso la obra "Mulher Palavra", escultura en bronce, en XXX Salão de Artes Plásticas de Rio Claro (Junio 2012). Participó en la Exposición de Artes Plásticas "ÁRVORE: uma reflexão sobre a obra de Thomaz Perina" con la obra "Espaço e tempo de Thomaz Perina" en el ITP (Campiñas, 2016), en el Laboratório de Artes de Franca (marzo-abril 2017) y en la Galería de Arte de la Escuela Comunitaria de Campiñas (mayo-junio de 2017). El Instituto de Geociencias de la Universidad Estatal de Campiñas fue sede de su exposición individual "Ilusões Concretas" en el año 2019.

Verónica Hollman / vhollman@conicet.gov.ar

Doctora en Ciencias Sociales (FLACSO- Buenos Aires), Master of Arts (University of British Columbia), Licenciada y Profesora en Geografía (Universidad Nacional del Comahue). Actualmente se desempeña como Investigadora Independiente del CONICET, con sede en el Instituto de Geografía "Romualdo Ardissone" de la Facultad de Filosofía y Letras de la Universidad de Buenos Aires. Es miembro de la Red internacional de investigación "Imagens, geografias e educação". También integra el Grupo de Estudio "Cultura, Naturaleza, Territorio" del Instituto de Geografía de la UBA. 